\title{
SEXUAL RISK BEHAVIOUR AND ITS DETERMINANTS AMONG men Who have Sex With men in Catalonia, Spain
}

\author{
C Folch (cft.ceescat.germanstrias@gencat.cat) ${ }^{1,2,3}, \mathrm{R}$ Muñoz ${ }^{1,4}, \mathrm{~K}_{\text {Zaragoza }}{ }^{1}, \mathrm{~J}$ Casabona ${ }^{1,2,5}$ \\ 1. Centre for Sexually Transmitted Infection and AIDS Epidemiological Studies of Catalonia (CEEISCAT) - ICO, Hospital \\ Universitari Germans Trias i Pujol, Badalona, Spain \\ 2. Ciber Epidemiología y Salud Pública (CIBERESP), Barcelona, Spain \\ 3. PhD Programme in Public Health and Methodology of Biomedical Research, Department of Pediatrics, Obstetrics and \\ Gynecology, and Preventive Medicine. Universitat Autònoma de Barcelona (UAB), Barcelona, Spain \\ 4. Stop Sida, Barcelona, Spain \\ 5. Department of Pediatrics, Obstetrics and Gynecology, and Preventive Medicine. Universitat Autònoma de Barcelona (UAB), \\ Barcelona, Spain
}

This article was published on 26 November 2009 .
Citation style for this article: Folch C, Muñoz R, Zaragoza K, Casabona J. Sexual risk behaviour and its determinants among men who have sex with men in Catalonia, Spain. Euro Surveill. 2009;14(47):pii=19415. Available online: http://www.eurosurveillance.org/ViewArticle.aspx?ArticleId=19415

\begin{abstract}
To evaluate the prevalence of sexual risk behaviours among men who have sex with men (MSM) in Catalonia and to identify sociodemographic, psychosocial, and behavioural factors associated with unprotected anal intercourse (UAI) with casual partners a convenience sample of 850 MSM was recruited in 2006. An anonymous questionnaire was used to explore risk behaviours during the previous 12 months. Logistic regression models were used to examine the variables associated with UAI. Mean age was 41 years and $20.4 \%$ were immigrants. Among those with casual partners (91.7\% of all respondents), $31.4 \%$ had UAI. The multivariate analysis revealed that the likelihood of UAI was higher in men who were HIV-positive (OR: 1.77), used more than four drugs before sex (OR: 4.90 for +6 ), were not from Spain (OR: 2.10 for Latin American; OR: 1.86 for other immigrants), had more than 20 sexual partners (OR: 1.56), met casual sex partners on the Internet (OR:1.45) and presented a high level of internalised homophobia (OR: 2.40). HIV/STI prevention programmes for MSM in Catalonia should incorporate activities that strengthen self-esteem, take into account the impact of internalised homophobia, and adapt to the sociocultural reality of immigrants. Furthermore, these programmes should also address substance abuse and alert HIV-positive men about the risk of HIV re-infection and transmission of other STI.
\end{abstract}

\section{Introduction}

In Europe, we have recently witnessed an increase in the number of new diagnoses of HIV infection in men who have sex with men (MSM) $[1,2]$ and in the number of other sexually transmitted infections (STI) [3] in particular among HIV-positive MSM [4].

In Catalonia, voluntary reporting of newly diagnosed HIV infections was implemented in January 2001 and a total of 4,082 cases were reported between January 2001 and December 2006. Of these, MSM accounted for $43.4 \%$ of male HIV cases in 2001 2006 [5]. Although there are no recent data on the true incidence of HIV in this group, a study on recently acquired infections in Spain found that MSM constituted $62.5 \%$ among the recent infections identified with the STARHS technique during 20032005, which seems to indicate that we may be seeing an increase in the number of new infections in this group [6].
The resurgence of syphilis and other STI in Barcelona reflects a trend of increasing risk behaviour in MSM, a notable proportion of whom are HIV-positive [7,8]. Recently, an outbreak of lymphogranuloma venereum was reported among MSM in Barcelona [9]. Moreover, a significant growth in the HIV prevalence among MSM (from 14.2\% in 1995 to $19.8 \%$ in 2006) has been observed in the sentinel surveillance system in Catalonia [5].

These increases in the prevalence of HIV infection and other STI are consistent with the increase in risk behaviours observed in MSM in other European cities $[10,11]$. For example, data from different surveys carried out in London in 1998 and 2003 showed an increase in the percentage of men reporting high risk sexual behaviour with a casual partner from $6.7 \%$ to $16.1 \%$ [12]. Studies in Catalonia have also shown a growing trend in reported sexual risk behaviours such as high number of sexual partners and unprotected anal intercourse (UAI) $[5,13]$. Among the reasons some authors give for these increases, particularly noteworthy are the use of alcohol and drugs before and during sexual intercourse $[14,15]$ and the use of Internet to search for and meet partners $[16,17]$. Furthermore, psychosocial factors such as externalised and internalised homophobia and discrimination can lead to low self-esteem that can in turn lead to an increase in risk behaviours, difficulties when negotiating safe sex, and substance abuse [1820].

A more in-depth analysis of the factors responsible for highrisk sexual practices is necessary in order to improve the design of preventive interventions aimed at reducing transmission of HIV and other STI in this group. The objectives of this study were to estimate the prevalence of reported sexual risk behaviours among MSM recruited in 2006 in Catalonia and to identify possible sociodemographic, psychosocial, and behavioural factors associated with UAI with casual partners.

\section{Methods}

HIV/STI behavioural surveillance among MSM began in Catalonia in 1993 as part of the Integrated HIV/STI Surveillance System 
(SIVES) [5]. To date, seven cross-sectional studies have been carried out in collaboration with the association Stop Sida. For the purpose of the present study, we analysed data from the most recent survey carried out in 2006. Given the difficulty in obtaining a representative sample of MSM, and with the aim of maximising the diversity of the group studied, we took a convenience sample from three saunas, two sex-shops, seven bars, and a public park that is frequented by gay men. These sites were selected from a larger list of gay venues screened prior to the survey and considered to represent a wide cross-section of MSM in Barcelona. Over a six-week period, four volunteers from Stop Sida handed out 2,735 questionnaires at the different sites. In addition, during the last

\section{TA B L E 1}

Sociodemographic and psychosocial characteristics and prevalence of HIV infection and other STI in a convenience sample of men who have sex with men in Catalonia, 2006 $(\mathbf{n}=\mathbf{8 5 0})$

\begin{tabular}{|c|c|c|}
\hline & $n$ & $\%$ \\
\hline \multicolumn{3}{|l|}{ Recruitment site } \\
\hline Sauna & 243 & 28.6 \\
\hline Sex-shop & 204 & 24.0 \\
\hline Park & 82 & 9.6 \\
\hline Bar & 107 & 12.6 \\
\hline Coordinadora Gay-Lesbiana & 214 & 25.2 \\
\hline \multicolumn{3}{|l|}{ Age (years) } \\
\hline $19-30$ & 106 & 12.7 \\
\hline$>30$ & 728 & 87.3 \\
\hline University education & 446 & 53.2 \\
\hline Immigrant & 173 & 20.4 \\
\hline \multicolumn{3}{|l|}{ Sexual orientation } \\
\hline Homosexual & 756 & 89.2 \\
\hline Bisexual & 72 & 8.5 \\
\hline Heterosexual & 4 & 0.5 \\
\hline Not resolved or does not know & 16 & 1.8 \\
\hline \multicolumn{3}{|l|}{ Degree of internalised homophobia ${ }^{1}$} \\
\hline $1-2.5$ & 63 & 7.5 \\
\hline$>2.5-4$ & 774 & 92.5 \\
\hline Insults and/or attacks (previous 12 months) & 93 & 11.0 \\
\hline HIV test (at any time) & 737 & 86.8 \\
\hline Self-reported prevalence of HIV $^{2}$ & 139 & 19.7 \\
\hline STI (at any time) & 535 & 64.5 \\
\hline \multicolumn{3}{|l|}{ STI (previous 12 months) ${ }^{3}$} \\
\hline Syphilis & 27 & 3.3 \\
\hline Gonorrhoea & 40 & 4.8 \\
\hline Urethritis & 21 & 2.5 \\
\hline Herpes & 14 & 1.7 \\
\hline Pubic lice & 64 & 7.7 \\
\hline Genital warts & 20 & 2.4 \\
\hline
\end{tabular}

${ }^{1}$ Heterosexuals excluded;

${ }^{2}$ Among those who had the HIV test and reported the results;

${ }^{3}$ Non-exclusive categories. weeks of recruitment, further 1,166 questionnaires were sent to all the members of the Coordinadora Gay-Lesbiana de Cataluña (GayLesbian Coordination Organization of Catalonia). It was possible to distinguish the questionnaires returned from the gay venues from those sent to the mailing list. The questionnaires were anonymous and self-administered and were accompanied by a prepaid envelope to be sent by post.

The questionnaire used was adapted from the one that had been developed and validated by the University Institute of Social and Preventive Medicine in Lausanne, Switzerland [21]. Questions on sexual behaviour referred to the period of 12 months preceding the survey. The information collected included sociodemographic characteristics such as age, educational level, and country of origin. Respondents were also asked about their sexual orientation and whether they had experienced insults or aggression. The level of internalised homophobia, that is the negative attitude men have about their homo/bisexuality, was estimated using seven statements on acceptance of their sexuality in which the replies went from 1 (totally agree) to 4 (do not agree) [22]. Once the internal consistency of the replies was calculated (Cronbach alfa, 0.823),

TA B L E 2

Sexual behaviour and use of alcohol and drugs before or during sexual intercourse in the previous 12 months in a convenience sample of men who have sex with men in Catalonia, $2006(n=850)$

\begin{tabular}{|c|c|c|}
\hline & n & $\%$ \\
\hline Use of alcohol & 533 & 63.8 \\
\hline \multicolumn{3}{|l|}{ Use of drugs ${ }^{1}$} \\
\hline Cannabis & 217 & 26.0 \\
\hline Cocaine & 157 & 18.8 \\
\hline Amphetamine & 38 & 4.6 \\
\hline Poppers & 341 & 40.8 \\
\hline Viagra & 110 & 13.2 \\
\hline Ketamine & 42 & 5.0 \\
\hline Methamphetamine & 25 & 3.0 \\
\hline \multicolumn{3}{|l|}{ Number of drugs used } \\
\hline 0 & 365 & 44.3 \\
\hline $1-3$ & 378 & 45.9 \\
\hline $4-6$ & 65 & 7.9 \\
\hline More than 6 drugs & 15 & 1.8 \\
\hline \multicolumn{3}{|l|}{ Number of male sexual partners } \\
\hline $1-10$ & 296 & 35.8 \\
\hline $11-20$ & 160 & 19.3 \\
\hline More than 20 & 371 & 44.9 \\
\hline Sex with a stable partner & 453 & 55.4 \\
\hline Sex with a casual partner & 776 & 91.7 \\
\hline UAI with a casual partner ${ }^{2}$ & 233 & 31.4 \\
\hline Meet casual partners on the Internet & 353 & 42.4 \\
\hline Has charged for sex & 34 & 4.1 \\
\hline
\end{tabular}

${ }^{1}$ Non-exclusive categories;

${ }^{2}$ Among those who reported having a casual partner;

UAI: unprotected anal intercourse 
TA B L E 3

Factors associated with unprotected anal intercourse with casual partners (previous 12 months) in a convenience sample of men who have sex with men in Catalonia, 2006. Univariate logistic regression analysis.

\begin{tabular}{|c|c|c|c|c|}
\hline & UAI \% & OR & $95 \%$ CI & p \\
\hline \multicolumn{5}{|l|}{ Age (years) } \\
\hline $19-30$ & 35.6 & 1.00 & & \\
\hline$>30$ & 31.2 & 0.82 & $0.51-1.31$ & 0.400 \\
\hline \multicolumn{5}{|l|}{ Recruitment site } \\
\hline Gay venues & 32.2 & 1.00 & & \\
\hline Mailing list: Coordinadora Gay- Lesbiana & 28.4 & 0.83 & $0.57-1.22$ & 0.346 \\
\hline \multicolumn{4}{|l|}{ Country of origin } & 0.002 \\
\hline Spain & 26.4 & 1.00 & & \\
\hline Immigrant (Latin America) & 45.1 & 2.28 & $1.43-3.64$ & 0.001 \\
\hline Immigrant (other) & 40.9 & 1.93 & $1.13-3.29$ & 0.017 \\
\hline No answer & 32.4 & 1.33 & $0.90-1.96$ & 0.149 \\
\hline \multicolumn{5}{|l|}{ Educational level } \\
\hline Non-university & 32.2 & 1.00 & & \\
\hline University & 30.5 & 0.92 & $0.68-1.27$ & 0.629 \\
\hline \multicolumn{5}{|l|}{ Sexual orientation } \\
\hline Homosexual & 30.5 & 1.00 & & \\
\hline Other ${ }^{1}$ & 39.0 & 1.46 & $0.91-2.35$ & 0.116 \\
\hline \multicolumn{5}{|l|}{ Insults and/or attacks ${ }^{2}$} \\
\hline No & 30.3 & 1.00 & & \\
\hline Yes & 41.3 & 1.61 & $1.00-2.60$ & 0.048 \\
\hline \multicolumn{5}{|l|}{ Internalised homophobia ${ }^{3}$} \\
\hline$>2.5-4$ & 30.1 & 1.00 & & \\
\hline 1-2.5 (high) & 45.5 & 1.94 & $1.13-3.34$ & 0.016 \\
\hline \multicolumn{5}{|l|}{ Use of alcohol ${ }^{2}$} \\
\hline No & 32.7 & 1.00 & & \\
\hline Yes & 31.1 & 0.93 & $0.67-1.29$ & 0.667 \\
\hline \multicolumn{4}{|l|}{ Number of drugs used ${ }^{2}$} & $<0.001$ \\
\hline No & 26.6 & 1.00 & & \\
\hline $1-3$ & 31.5 & 1.27 & $0.90-1.79$ & 0.172 \\
\hline $4-6$ & 46.8 & 2.43 & $1.39-4.25$ & 0.002 \\
\hline More than 6 drugs & 76.9 & 9.21 & $2.47-34.31$ & 0.001 \\
\hline \multicolumn{5}{|l|}{ Sex with a stable partner ${ }^{2}$} \\
\hline No & 32.5 & 1.00 & & \\
\hline Yes & 28.8 & 0.84 & $0.61-1.16$ & 0.294 \\
\hline \multicolumn{4}{|l|}{ Number of male sexual partners ${ }^{2}$} & $<0.001$ \\
\hline $1-10$ & 24.7 & 1.00 & & \\
\hline $11-20$ & 23.7 & 0.95 & $0.58-1.54$ & 0.831 \\
\hline More than 20 & 39.1 & 1.96 & $1.35-2.86$ & 0.000 \\
\hline \multicolumn{5}{|l|}{ Met casual partners on the Internet $^{2}$} \\
\hline No & 27.5 & 1.00 & & \\
\hline Yes & 35.7 & 1.46 & $1.07-2.00$ & 0.017 \\
\hline \multicolumn{5}{|l|}{ Have you charged for sex² } \\
\hline No & 30.6 & 1.00 & & \\
\hline Yes & 45.5 & 1.89 & $0.93-3.82$ & 0.076 \\
\hline \multicolumn{5}{|l|}{$\mathrm{STI}^{2}$} \\
\hline No & 30.4 & 1.00 & & \\
\hline Yes & 35.2 & 0.81 & $0.55-1.18$ & 0.271 \\
\hline \multicolumn{5}{|l|}{ Self-reported HIV result } \\
\hline Negative/unknown & 28.6 & 1.00 & & \\
\hline Positive & 43.8 & 1.95 & $1.32-2.89$ & 0.001 \\
\hline
\end{tabular}

${ }^{1}$ Bisexual, heterosexual, not resolved, or does not know;

2Previous 12 months;

${ }^{3}$ Heterosexuals excluded;

OR: Odds ratio 
the variable was calculated for each individual as the mean of responses to the seven statements using values ranging from 1 (high internalised homophobia) to 4 (no internalised homophobia). Furthermore the questionnaire collected data on the use of Internet to make contact with sexual partners, sexual practices with stable and casual partners, use of condoms, number of sexual partners, use of alcohol and drugs before or during sexual intercourse, selfreported HIV serostatus, and previous STI. UAI with casual partners was defined as inconsistent use of condoms during anal intercourse with these partners in the previous 12 months.

Univariate and multivariate logistic regression models were used to evaluate the sociodemographic, psychosocial, and behavioural variables associated with UAI. A final multivariate model was performed with inclusion of all variables that were significantly associated with UAI in univariate models ( $p$ value $<0.10$ ) and remained significantly associated in the final multivariate model. Adjusted odds ratio (AOR) and their respective 95\% confidence intervals $(\mathrm{Cl})$ were calculated. The calibration of the models was tested using the Hosmer-Lemeshow goodness-of-fit test. Statistical significance was set at 0.05 .

\section{Results}

Of the 3,901 questionnaires distributed, 877 were returned, giving the response rate of $22.5 \%$ (23.9\% for questionnaires handed out at gay venues and $19 \%$ for those sent to the mailing list). The analysis was carried out among men who reported having had sexual relations with men during the previous 12 months ( $n=850)$. Of the men included in the study, the mean age of the respondents was 41 years (range 19-76), more than half had a university education, and $20.4 \%$ were immigrants, mainly from Latin America (11.5\%). Most men reported that their sexual orientation was homosexual $(89.2 \%)$, further $8.5 \%$ characterised themselves as bisexual; and $11.0 \%$ of the respondents had experienced insults and/or attacks in the previous year because of their sexual orientation. We found that $7.5 \%$ of homo/bisexuals had a high degree of internalised homophobia with values lower than 2.5 (Table 1 ).

The self-reported prevalence of HIV infection among those who had been tested for HIV and gave their result was $19.7 \%$. As for STI, 64.5\% reported having had an infection in their lifetime, and $4.8 \%$ and $3.3 \%$ reported having been diagnosed with respectively gonorrhoea and syphilis during the previous year (Table 1). Among

\section{T A B L E 4}

Factors associated with unprotected anal intercourse with casual partners (previous 12 months) in a convenience sample of men who have sex with men in Catalonia, 2006. Final multivariate logistic regression model*

\begin{tabular}{|c|c|c|c|}
\hline & AOR & $95 \%$ CI & $p$ \\
\hline \multicolumn{3}{|l|}{ Country of origin } & 0.014 \\
\hline Spain & 1.00 & & \\
\hline Immigrant (Latin America) & 2.10 & $1.24-3.56$ & 0.006 \\
\hline Immigrant (other) & 1.86 & $1.04-3.32$ & 0.036 \\
\hline No answer & 1.37 & $0.88-2.12$ & 0.161 \\
\hline \multicolumn{4}{|l|}{ Internalised homophobia $^{1}$} \\
\hline$>2.5-4$ & 1.00 & & \\
\hline 1-2.5 (high) & 2.40 & $1.25-4.64$ & 0.009 \\
\hline \multicolumn{3}{|l|}{ Number of drugs used ${ }^{2}$} & 0.05 \\
\hline No & 1.00 & & \\
\hline $1-3$ & 1.11 & $0.76-1.62$ & 0.590 \\
\hline $4-6$ & 1.76 & $0.95-3.25$ & 0.071 \\
\hline More than 6 drugs & 4.90 & $1.23-19.5$ & 0.024 \\
\hline \multicolumn{3}{|l|}{ Number of male sexual partners ${ }^{2}$} & 0.002 \\
\hline $1-10$ & 1.00 & & \\
\hline $11-20$ & 0.71 & $0.42-1.21$ & 0.208 \\
\hline More than 20 & 1.56 & $1.03-2.38$ & 0.036 \\
\hline \multicolumn{4}{|l|}{ Met casual partners on the Internet $^{2}$} \\
\hline No & 1.00 & & \\
\hline Yes & 1.45 & $1.10-2.06$ & 0.042 \\
\hline \multicolumn{4}{|l|}{ Self-reported HIV result } \\
\hline Negative/unknown & 1.00 & & \\
\hline Positive & 1.77 & $1.14-2.74$ & 0.011 \\
\hline
\end{tabular}


HIV-positive men these percentages were higher $-8.8 \%$ and $9.5 \%$, respectively.

There was a high prevalence of drug use before or during sexual intercourse in the previous 12 months. The most widely used were poppers, cannabis, and cocaine $(40.8 \%, 26 \%$, and $18.8 \%$, respectively); $28.6 \%$ consumed two or more different drugs (Table 2).

Almost half $(44.9 \%)$ of those surveyed reported having had sexual relations with more than 20 male partners and $55.4 \%$ reported having had a stable partner in the previous 12 months. Among those who had sexual relations with at least one casual partner in the past 12 months (91.7\%), 31.4\% had UAI. Of those who had UAI with casual partners, $66.7 \%$ never asked the casual partners about their HIV serostatus. Internet had been the medium for finding a casual partner for $42.4 \%$ of all respondents, and $4.1 \%$ had received money in exchange for sexual relations with other men during the last 12 months (Table 2).

Table 3 shows the univariate logistic regression model for the variables associated with UAI. The final multivariate model showed a significant relationship between country of origin and UAI (Table 4). Immigrants, particularly from Latin America, were more likely to have had UAI with casual partners in the previous 12 months (OR: 1.86 and OR, 2.10, respectively). Furthermore, men who found it difficult to live with their homo/bisexuality and had a high level of internalised homophobia were also more likely to have unprotected sex with casual partners (OR: 2.40). Consuming several drugs (OR, 4.90 for $>6$ drugs), the number of sexual partners (OR:1.56 for $>20$ ) and finding casual partners on the Internet (OR: 1.45) were also significantly associated with UAI in the multivariate analysis. Finally, being HIV-positive was associated with a greater probability of having unprotected sex (OR: 1.77).

\section{Discussion}

Our results reveal a high prevalence of sexual risk behaviour among MSM in Catalonia, since almost half of the participants reported having had sex with more than 20 partners during the previous year, and $31.4 \%$ of those who reported having had casual partners had unprotected sex with these partners. Both these proportions were higher than in previous surveys [5]. These data are consistent with those of other studies [10-12]. Strategies aimed at reducing the risk of HIV transmission, such as serosorting (i.e. looking for partners with the same serostatus in order to maintain unprotected sexual relations), have been described [23-25]. However, these strategies carry an important risk of transmission since in many cases the serostatus is assumed $[26,27]$. In our study, $66.7 \%$ of men who had UAl with casual partners never asked about the serostatus of their partner, although a proportion of the reported UAI could have involved partners with the same serostatus, by chance only. This finding agrees with those of another study in Barcelona in which most of the MSM interviewed reported not having known the serostatus of their partner before engaging in sexual relations [26].

One of the factors associated with UAI is country of origin, as immigrants - particularly those from Latin America - have been described to be at greater risk of HIV infection [28]. In studies carried out among MSM in the United States, Latin Americans reported higher rates of UAI, even in comparison with other minority groups [29]. The racism, homophobia, and poverty these men experience often make it difficult to adopt safe practices and hence increase their vulnerability to HIV/STI.

Psychosocial factors also play a role in protecting oneself from HIV/STI. Our results indicate that those who find it more difficult to live with their sexual orientation and who have negative reactions and attitudes toward their own homo/bisexuality are more likely to engage in sexual risk practices. This is the first time we have analysed in our setting the association among the internalised homophobia and sexual risk behaviours described by other authors $[18,19]$. On the one hand, internalised homophobia has been reported to be an obstacle to prevention campaigns [18], and, on the other, it has been associated with low self-esteem and greater consumption of alcohol and drugs, which do not favour the practice of safe sex [19]. Future studies should therefore analyse psychosocial aspects in more detail, since they are important risk factors that must be incorporated in prevention messages.

Having a larger number of sexual partners was associated with a greater probability of sexual practices involving a greater risk of $\mathrm{HIV/STI}$. This finding is consistent with those of other European studies $[10,30]$. Therefore, the increasingly widespread use of Internet as a means of making contact with sexual partners that has been observed in recent years $[16,17,31]$ should be borne in mind, since this medium makes it easier to meet more sexual partners, thus increasing the vulnerability of MSM to HIV/STI. Indeed in our study, MSM who met sexual partners on the Internet were more likely to report UAI with casual partners, and this has also been observed in other studies $[16,17]$. The association between risky sexual behaviours and meeting partners online needs to be further explored. Online HIV/STI prevention campaigns could prove extremely useful in this group in the future.

Prevention in HIV-positive MSM continues to be a challenge, since this group are more likely than HIV-negative men or men whose serostatus is unknown to engage in sexual risk practices with casual partners, as reported by other authors $[28,32]$. Some authors stress that HIV-positive men sometimes use serosorting as a risk reduction strategy, although this has not proven efficient for reducing the risk of re-infection by HIV [33] or other STI [4]. Furthermore, a recent study of HIV-positive MSM in the UK highlighted that very few men exclusively practiced serosorting [34]. The reasons for the high prevalence of sexual risk behaviours in HIV-positive MSM include the availability of highly active antiretroviral therapy (HAART), access to Internet, increased substance use, and the stigma or discrimination MSM experience [34].

Finally, in line with other published studies [14,15,35], we found that the use of alcohol and drugs by MSM before and during sex shows a clear association with unprotected sexual relation, which stresses the need to include substance use in future prevention messages.

The main limitation of our study is that we are unable to generalise our results, as the sample was a non-probability sample and, therefore, does not represent all MSM in Catalonia. However, we did try to diversify as much as possible the places and times of the questionnaire distribution in order to minimise this bias. Furthermore, we cannot rule out bias caused by memory or bias caused by underreporting of some risk practices or the self-reported result of an HIV test. Nevertheless, the fact that the questionnaire was self-completed with no identifying personal information could have helped to reduce these types of bias. Another limitation of the 
study is the low return rate, although this was greater than in other similar studies [31,36]. Lastly, this is a cross-sectional study and so it is not possible to establish the direction of any association between risk factors and sexual risk practices.

Despite these limitations, we believe that the results of our study provide a valid indication of a high prevalence of sexual risk practices among MSM in Catalonia. This prevalence has increased with respect to previous surveys, which stresses the need to intensify interventions aimed at preventing transmission of HIV/ $\mathrm{STI}$ in this group. It seems that current prevention campaigns based on spreading information about safe sex are insufficient and fail to address other factors that influence the use of condoms, such as internalised homophobia or social and cultural background. These campaigns should incorporate activities that take into account the impact of internalised homophobia and strengthen self-esteem of gay people, as well as adapt to the sociocultural reality of immigrants. Furthermore, these programmes should also include information on the effects of mixing drugs and sex. Preventive interventions aimed specifically at HIV-positive MSM must be reinforced by insisting on the possibility of HIV re-infection and transmission of other STI and taking into account factors such as stigma and discrimination which often hinder HIV-positive men from taking protective measures against infection. Similarly, new technologies, such as Internet, will play a key role in developing and spreading messages aimed at preventing the transmission of HIV/STI in the future.

Finally, we should attempt to encourage a shift in preventive strategies, from those based only on information campaigns to those based on the implementation of services aimed specifically at MSM which can integrate both preventive and clinical interventions at community level. New diagnostic technologies, such as rapid testing, not only for HIV but also for other STI, provide a good opportunity to expand access to testing, and therefore to counselling and other preventive interventions. Knowledge gained during recent years on network analysis and the role of sexual networks in the spread of HIV should be applied to Internet to deliver preventive interventions to MSM. Bio-behavioural monitoring will continue to be a basic tool to evaluate such approaches.

\section{Acknowledgements}

The authors thank Stop Sida for carrying out the survey fieldwork, and all the men who voluntarily replied to the questionnaire.

The study was supported in part by the following: Direcció General de Salut Pública, Departament de Salut, Generalitat de Catalunya; Agència de Gestió d'Ajuts Universitaris i de Recerca - AGAUR (2005/SGR/00505), Departament d'Universitats, Recerca i Societat de la Informació, de la Generalitat de Catalunya; and Centro de Investigación Biomédica en Red (CIBER) - CIBER de Epidemiología y Salud Pública (CIBERESP).

\section{References}

1. Likatavicius G, Klavs I, Devaux I, Alix J, Nardone A. An increase in newly diagnosed HIV cases reported among men who have sex with men in Europe, 2000-6: implications for a European public health strategy. Sex Transm Inf. 2008;84(6):499-505.

2. Herida M, Alix J, Devaux I, Likatavicius G, Desenclos JC, Matic S, et al. HIV AIDS in Europe: epidemiological situation in 2006 and a new framework for surveillance. Euro Surveill. 2007;12(47):pij=3312. Available from: http://www. eurosurveillance.org/ViewArticle.aspx?ArticleId $=3312$

3. Fenton KA, Lowndes CM. Recent trends in the epidemiology of sexually transmitted infections in the European Union. Sex Transm Infect. 2004;80(4):255-63.
4. Dougan S, Evans BG, Elford J. Sexually transmitted infections in Western Europe among HIV-positive men who have sex with men. Sex Transm Dis. 2007;34(10):783-90.

5. Centre for Sexually Transmitted Infection and AIDS Epidemiological Studies of Catalonia (CEEISCAT). Sistema integrat de vigilància epidemiològica de Sida/VIH/ITS a Catalunya (SIVES) [Integrated system of epidemiological surveillance of AIDS/HIV/STI in Catalonia]. Technical document 18. Barcelona: Generalitat de Catalunya, Departament de Salut; 2006. Catalonian. Available from: http://www.ceescat.org/Index_Ing.htm

6. Romero A, González V, Granell M, Matas L, Esteve A, Martró E, et al, Recently acquired HIV infection in Spain (2003-2005): introduction of the serological testing algorithm for recent HIV seroconversion. Sex Transm Infect. 2009;85(2):106-10.

7. Vall-Mayans M, Casals M, Vives A, Loureiro E, Armengol P, Sanz B. Reemergence of infectious syphilis among homosexual men and HIV coinfection in Barcelona, 2002-2003. Med Clin (Barc). 2006;126(3):94-6. Spanish.

8. Tortajada C, de Olalla PG, Pinto RM, Bosch A, Caylà J. Outbreak of hepatitis A among men who have sex with men in Barcelona, Spain, September $2008-$ March 2009. Euro Surveill. 2009;14(15):pii=19175. Available from: http://www. eurosurveillance.org/ViewArticle.aspx?ArticleId=19175

9. Vall Mayans M, Caballero E, Garcia de Olalla P, Armengol P, Codina M, Barberà $M$, et al. Outbreak of lymphogranuloma venereum among men who have sex with men in Barcelona 2007/08 - an opportunity to debate sexual health at the EuroGames 2008. Euro Surveill. 2008;13(25):pij=18908. Available from: http://www.eurosurveillance.org/ViewArticle.aspx?ArticleId $=18908$

10. Cowan SA, Haff J. HIV and risk behaviour among men who have sex with men in Denmark - the 2006 Sex Life Survey. Euro Surveill. 2008:13(48):pij=19050. Available from: http://www.eurosurveillance.org/ViewArticle. aspx?ArticleId $=19050$

11. Hart $\mathrm{G}$, Williamson L. Increase in HIV sexual risk behaviour in homosexual men in Scotland, 1996-2002: prevention failure? Sex Transm Infect. 2005;81(5):367-2.

12. Elford J, Bolding G, Davis M, Sherr L, Hart G. Trends in sexual behaviour among London homosexual men 1998-2003: implications for HIV prevention and sexual health promotion. Sex Transm Infect. 2004:80(6):451-4.

13. Folch C, Casabona J, Muñoz R, González V, Zaragoza K. Incremento en la prevalencia del VIH y en las conductas de riesgo en hombres que tienen sexo con hombres: 12 años de encuestas de vigilancia conductual en Cataluña [Increase in the prevalence of HIV and sexual risk behaviour in men who have sex with men: 12 years of behavioural surveillance in Catalonia]. Gac Sanit. Forthcoming.

14. Drumright LN, Little SJ, Strathdee SA, Slymen DJ, Araneta MR, Malcarne VL, et al. Unprotected anal intercourse and substance use among men who have sex with men with recent HIV infection. J Acquir Immune Defic Syndr. 2006;43(3):344-50.

15. Operario D, Choi KH, Chu PL, McFarland W, Secura GM, Behel S, et al. Prevalence and correlates of substance use among young Asian Pacific Islander men who have sex with men. Prev Sci. 2006;7(1):19-29.

16. Garofalo R, Herrick A, Mustanski BS, Donenberg GR. Tip of the iceberg: young men who have sex with men, the Internet, and HIV risk. Am J Public Health. 2007;97(6):1113-7.

17. Ogilvie GS, Taylor DL, Trussler T, Marchand R, Gilbert M, Moniruzzaman A, et al. Seeking sexual partners on the Internet: A marker for risky sexual behaviour in men who have sex with men. Can J Public Health. 2008;99(3):185-8.

18. Huebner DM, Davis MC, Nemeroff CJ, Aiken LS. The impact of internalized homophobia on HIV preventive interventions. Am J Community Psychol. 2002;30(3):327-48.

19. Williamson IR. Internalized homophobia and health issues affecting lesbians and gay men. Health Educ Res. 2000;15(1):97-107.

20. Jarama S, Kennamer J, Poppen P, Hendricks M, Bradford J. Psychosocial, behavioral, and cultural predictors of sexual risk for HIV infection among Latino men who have sex with men. AIDS Behav. 2005;9(4):513-23.

21. Moreau-Gruet F, Dubois-Arber F. Evaluation de la stratégie de prévention du Sida en Suisse: Phase 6: 1993-1995. Les hommes aimant d'autres hommes. Etude 1994. [Evaluation of the AIDS prevention strategy in Switzerland, phase 6: 1993-1995. Men who have sex with men. 1994 study.]. Lausanne: Institut Universitaire de Médecine Sociale et Préventive; 1995.

22. Herek GM, Cogan JC, Gillis JR, Glunt EK. Correlates of internalized homophobia in a community sample of lesbians and gay men. J Gay Lesbian Med Assoc. 1997;2:17-25.

23. Mao L, Crawford JM, Hospers HJ, Prestage GP, Grulich AE, Kaldor JM, et al. "Serosorting" in casual anal sex of HIV-negative gay men is noteworthy and is increasing in Sydney, Australia. AIDS. 2006;20(8):1204-6.

24. Parsons JT, Schrimshaw EW, Wolitski RJ, Halkitis PN, Purcell DW, Hoff CC, et al. Sexual harm reduction practices of HIV-seropositive gay and bisexual men: serosorting, strategic positioning, and withdrawal before ejaculation. AIDS. 2005;19 Suppl 1:S13-S25 
25. Truong HM, Kellogg T, Klausner JD, Katz MH, Dilley J, Knapper K, et al. Increases in sexually transmitted infections and sexual risk behaviour without a concurrent increase in HIV incidence among men who have sex with men in San Francisco: a suggestion of HIV serosorting? Sex Transm Infect. 2006;82(6):461-6.

26. Fernández-Dávila P. Amigos con derecho a roce: una oportunidad para contraer la infección por el virus de la inmunodeficiencia humana en hombres homo/ bisexuales con prácticas sexuales de alto riesgo ["Sex buddies": a high risk behavior for contracting HIV among homo/bisexual men]. Gac Sanit. 2007;21(6):471-8. Spanish.

27. Butler DM, Smith DM. Serosorting can potentially increase HIV transmissions. AIDS. 2007;21(9):1218-20.

28. Schwarcz S, Scheer S, McFarland W, Katz M, Valleroy L, Chen S, et al. Prevalence of HIV infection and predictors of high-transmission sexual risk behaviors among men who have sex with men. Am J Public Health. 2007;97(6):1067-75.

29. Díaz RM, Ayala G. Social discrimination and health: The case of latino gay men and HIV risk. Washington: The Policy Institute of the National Gay and Lesbian Task Force; 2001. Available from: http://www.thetaskforce.org/downloads/ reports/reports/SocialDiscriminationAndHealth.pdf

30. Hichson F, Weatherburn P, Reid D, Jessup K, Hammond G. Consuming passions: findings from the United Kingdom Gay Men's Sex Survey 2005. London: Sigma research; 2007. Available from: http://www.sigmaresearch.org.uk/downloads/ report07c.pdf

31. Fernández-Dávila P, Zaragoza Lorca K. Internet y riesgo sexual en hombres que tienen sexo con hombres [Internet and sexual risk in men who have sex with men]. Gac Sanit. 2009;23(5):380-7. Spanish.

32. Holtgrave DR, Crosby R, Shouse RL. Correlates of unprotected anal sex with casual partners: a study of gay men living in the southern United States. AIDS Behav. 2006;10(5):575-8.

33. Campbell MS, Gottlieb GS, Hawes SE, Nickle DC, Wong KG, Deng W, et al. HIV-1 superinfection in the antiretroviral therapy era: are seroconcordant sexual partners at risk? PLoS One. 2009:4(5):e5690.

34. Bourne A, Dodds C, Keogh P, Weatherburn P, Hammond G. Relative Safety II risk and unprotected anal intercourse among gay men with diagnosed HIV. London: Sigma research; 2009. Available from: http://www.sigmaresearch.org. uk/files/report2009d.pdf

35. Folch C, Marks G, Esteve A, Zaragoza K, Muñoz R, Casabona J. Factors associated with unprotected sexual intercourse with steady male, casual male, and female partners among men who have sex with men in Barcelona, Spain. AIDS Educ Prev. 2006;18(3):227-42.

36. Dubois-Arber F, Moreau-Gruet F. Men having sex with men and HIV/AIDS prevention in Switzerland: 1987-2000. Euro Surveill. 2002;7(2):pii=347. Available from: http://www.eurosurveillance.org/ViewArticle. aspx?ArticleId=347 